\title{
Stability Assessment and Optimization Design of Lakeside Open-Pit Slope considering Fluid-Solid Coupling Effect
}

\author{
Wenchen Fan, Ping Cao, Ke Zhang, Kaihui Li, and Chong Chen \\ School of Resources and Safety Engineering, Central South University, Changsha, Hunan 410083, China \\ Correspondence should be addressed to Wenchen Fan; fwch_csu@126.com
}

Received 29 May 2015; Revised 14 August 2015; Accepted 18 August 2015

Academic Editor: Renata Archetti

Copyright ( 2015 Wenchen Fan et al. This is an open access article distributed under the Creative Commons Attribution License, which permits unrestricted use, distribution, and reproduction in any medium, provided the original work is properly cited.

\begin{abstract}
Chengmenshan copper mine, located at Jiujiang city in the Jiangxi Province, is a rarely lakeside open-pit mine in China. Since the open-pit is very close to Sai Lake, the seasonally changed water level and the distance between lake and slope have great influence to the stability of open-pit slope. Based on the drill data and geological sections, a numerical model of the slope is built. With the fluid-mechanical interaction associated, the stability of the slopes is numerically analyzed, in which different lake water levels and lake-slope distances are taken into consideration. The comparative analysis shows that a larger lake-slope distance can promise better slope stability and weaken the sensitivity of slope stability to water. The stability of slopes with different heights is analyzed to find that the stability weakens and the sensitivity is enhanced with the height increasing. To the most serious situation, the slope height and the lake water level being $238 \mathrm{~m}$ and $17.2 \mathrm{~m}$, respectively, the $F_{s}$ value equals 1.18945 which is extremely closed to the allowable safety factor of 1.20 for slope design. According to the minimum $F_{s}$ for slope design, the minimum distance between lake and open-pit slope is found to be $60 \mathrm{~m}$.
\end{abstract}

\section{Introduction}

According to a large number of engineering practices, landslides of natural and artificial slopes often happen after the heavy rain or continuous rainfall. The failure of reservoir bank slopes occurs in sharp decline of water level, long-term immersion, and hydrological cycle. It shows that the seepage of ground water in the slope makes great difference to the stability of slope.

Theoretical study and practical experience show that open-pit slopes usually experience four stages from excavation completion to collapse: the elastic stage, the nonlinear deformation stage, creep deformation stage, and the collapse stage. According to the Mohr-Coulomb criteria, the shear strength of rock decreases greatly when encountering with water. To rock slopes, this means a great reduction of stability. With the development of the numerical calculation, many modules in kinds of numerical software have been developed to realize the hydromechanical coupling in fractured rock mass [1-4]. The Itasca software FLAC $^{3 \mathrm{D}}$ based on fast Lagrangian method can be used to simulate the flow of fluid through a permeable solid [5], and the pore pressure of the fluid will change in response to the change of mechanical volume.

A lot of studies have been done to learn the coupling mechanism of water pressure and rock mass stress [612]. Rutqvist and Stephansson [13] and Wang [14] recognized two types of hydromechanical coupling: direct and indirect. Direct coupling occurs through deformation and pore fluid interactions. Indirect coupling is where changes in the mechanical or hydraulic processes affect each other through changes in mechanical and hydraulic properties. The deformation of pit slope, which is largely inelastic with creep and slip on structures, causes irreversible changes in the rock mass and hydraulic properties of the mass and is largely indirect coupling.

The stability of mine slopes depends on the designs. Implicitness or explicitness in this design process is an acceptance of some instability or a certain percentage of failure $[15,16]$. Usually the deformations after excavation and critical factors that may cause landslides are taken into consideration in the mine slope design process. A lot of preanalyses are 
made to make sure that the mine slope attains a certain safety coefficient. In some sense, the slope we designed is an acceptance of some instability or a certain percentage of failure [17]. In fact, the groundwater seepage has serious influence on the stability of mine slope. The deformation of slope rock mass will result in the change of cracks and porosity and then the change of seepage effect. Sartori et al. [18] described that the Randa landslide was a devastating rock landslide along with high pressure infiltration water injection. Cappa et al. [19] found that the infiltration of seasonal rainfall accelerated the process of Clapière landslide.

Many methods have been carried out to study the influence of seepage on slope stability. Saada et al. [20] adopted the limit analysis method to evaluate the slope stability under seepage. Lv et al. [21] established the mathematical model of rock mass damage under the influence of seepage. The mathematical model was used to analyze the stability of coal mining open-pit slope, and the result indicated that the reduction of effective stress caused the failure of the slope. Chu-Agor et al. [22] performed a series of experiments of the slope instability under the action of water pressure, and the results were applied to the mountain slope stability analysis. Srivastava et al. [23] adopted FLAC5.0 to analyze the influence of groundwater seepage on the stability of slopes with different slope conditions and material properties.

Numerical modeling is an efficient method in the analysis of slope stability under the action of seepage. The Itasca software FLAC ${ }^{3 D}$ has been widely used in the analysis of underground tunnels, open-pit mining, and underground mining complicating gravity, groundwater, and other factors. But there are some difficulties in the construction of a complex numerical model by employing $\mathrm{FLAC}^{3 \mathrm{D}}$ alone. Some researchers constructed the model by the way of integrating SURPAC and FLAC ${ }^{3 \mathrm{D}}$ [24-28]. In this study, DIMINE, a $3 \mathrm{D}$ geological model construction software, is adopted to construct the geologic model of a lakeside open-pit copper mine. Then the model is imported into FLAC ${ }^{3 D}$ with the assistance of Midas-GTS. The open-pit slope stability is finally assessed numerically by FLAC ${ }^{3 \mathrm{D}}$ associated with the lake water. Comparing the safety factors of slope under different heights of water level, a reasonable distance between lake and open-pit slope is determined.

\section{Engineering Background}

Chengmenshan copper mine is an open-pit mining located at suburb of Jiujiang city, Jiangxi Province, China. It is in the middle-lower reaches of the Yangtze river region. The terrain slopes gently. Ruichang River flows from the west of the openpit (Figure 1), across the Sai Lake in the north and east of the open-pit, and then ends at Yangtze river. The open-pit is just beside the Sai Lake (Figure 2).

In the preanalysis area of the open-pit, stratum in the mining area belongs to upper Pleistocene series mostly. The metal ore exits in the magmatic rock in the middle area of the mining area. The bed rocks of Sai Lake are the Triassic and Permian limestone of Carboniferous. The limestone is the main aquifer of the mining area. Due to the long-term immersing of the ground water, there exist lots of karst caves,

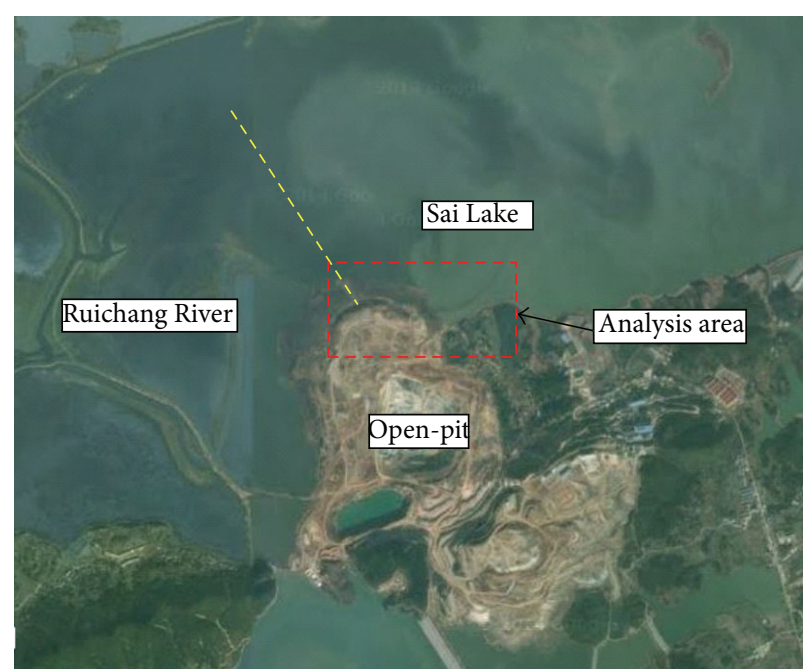

FIGURE 1: Geographic location of Chengmenshan copper mine.

dissolved holes, and fissured caverns in the bedrock. It shows a phenomenon that the karst is better developed in the shallow rock strata than the deep strata. The moisture content of the rock changes with the karst development degree. The rock property is very poor because of the existence of the karst.

The elevation of the open-pit bottom is currently about $-60 \mathrm{~m}$; this means the height of the slope is about $100 \mathrm{~m}$. But as time goes on, the mining area will extend with the mining depth increasing and the open-pit will get closer to Sai Lake. The water surface acreage of Sai Lake is about $970 \mathrm{~km}^{2}$. Ruichang River is the main water resource of Sai Lake. When the rainy season comes, the water level of Ruichang River will rise and result in the rise of water level of Sai Lake. Furthermore, the water of Yangzi River that is not far from Sai Lake will influence the water level of Sai Lake. On the contrary, the water level will fall after rise in dry season. Historical hydrological survey data show that the highest water level of Sai Lake is $+25.2 \mathrm{~m}$ and the lowest is $+10.4 \mathrm{~m}$.

Chengmenshan copper mine is currently in the continuous stage of the second phase and third phase. Ore body of copper in Chengmenshan distributes from the shallow strata to the deep, and there are lots of copper exits below $-300 \mathrm{~m}$. In order to protect the environment surrounding the lake and ensure safety production, in the end of third phase the open-pit mining will be changed into underground mining. The main mission at present is to make a decision about the ultimate size, the depth of open-pit, and the distance between lake and the open-pit to make sure of a safe and reasonable environment for underground mining in the future. The preanalysis of the open-pit slope stability under the influence of a changeable level of lake water becomes a difficult but most important task.

\section{Numerical Model and Boundary Conditions}

3.1. Numerical Model Construction. In order to get the accurate geological model of the slope, the entire numerical model of the open-pit slope near the lake is built by integrating 


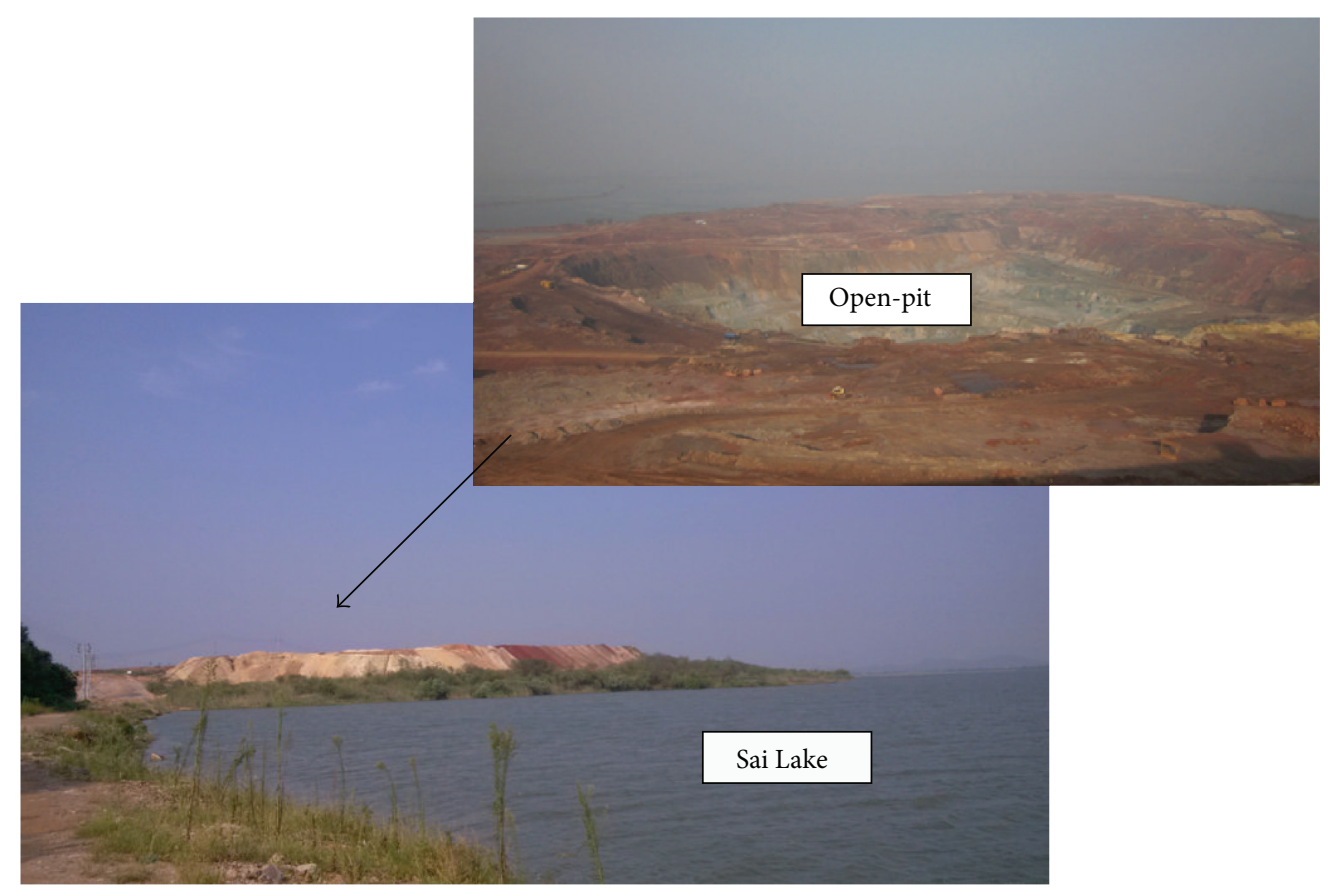

Figure 2: The circumstances surround the open-pit.

DIMINE and FLAC ${ }^{3 \mathrm{D}}$ based on the geological data. The implementation of the program is illustrated as a flow chart in Figure 3. Early when the mining was found, a series of geological prospecting works were finished, and many geological sections of exploratory lines were plotted based on the drilling data. Firstly, import the sections into DIMINE in sequence, set the boundary lines of every lithologic into a layer separately, and extend the profile line to 3D geological model by the way of Boolean operation (Figure 4(b)). Secondly, build the weathering interface based on the drilling data and insert the interface into the 3D model according to the coordinates. Finally, import the designed slope model (Figure 4(b)) to intersect the 3D model to get the open-pit slope geological model. Then we can get the geological section of the lakeside open-pit slope in Figure 4(c).

The lithology of every strata from ground surface to the bottom is: Quaternary upper Pleistocene Series $\left(Q_{3}\right)$, Triassic Daye limestone (T1d), Permian Changxing limestone (P2c), Permian Longtan limestone (P2l), Permian Maokou limestone (P1m), Permian Qixia limestone (P1q), Permian Liangshan limestone (P1l), and Yanshanian granodioriteporphyry $(\gamma \delta \pi)$.

In the section the slope steps are not taken into account (Figure 4(c)). The whole slope is divided into two stages by the weathering line: the weathered stage above the weathering line and the unweathered stage below that. Learning from the section, the elevation of the slope top is $+38 \mathrm{~m}$ and the bottom is $-238 \mathrm{~m}$, so the height of the whole slope is $276 \mathrm{~m}$. The elevation of weathering line in this area is about $-100 \mathrm{~m}$. According to the slope design, the overall dip angles of the weathered stage, the unweathered stage, and the whole open-pit slope are $41^{\circ}, 48^{\circ}$, and $44^{\circ}$, respectively. The lake is at the top-right corner of the model. The elevation of lakebed is $+8 \mathrm{~m}$.
Considering that the $3 \mathrm{D}$ seepage calculation based on complicated geological model is very difficult, the plane strain mode in FLAC ${ }^{3 \mathrm{D}}$ numerical model is used in this study, and this methodology has previously been applied by many researchers [29-33]. The geological section model cannot be imported to FLAC ${ }^{3 \mathrm{D}}$ directly, so with the help of Midas-GTS, the model is got meshed. Then the grid points and elements data are exported into FLAC ${ }^{3 \mathrm{D}}$ from Midas-GTS and the plane strain numerical model is established (Figure 5).

3.2. Boundary Conditions and Calculation Parameters. In the numerical modeling, the displacement boundary conditions of the model include (a) fixed displacements in $X$-, $Y$-, and $Z$-direction at the bottom boundary of the model; (b) fixed displacements in $X$-direction at the left and right boundaries; (c) fixed displacement in $Y$-direction of the total model; (d) free boundary at the slope top, slope surface, slope bottom face, and the faces in lake area.

The infiltration faces of the lake water are the lake bottom and the lake bank, and the outflow faces are the slope surface and the slope bottom face (Figure 4). The pore water pressure of the outflow faces is fixed $0 \mathrm{MPa}$. The right boundary, the bottom boundary, and the left boundary are impermeable boundaries set by default in FLAC ${ }^{3 \mathrm{D}}$. The lake water is considered as a seepage force and a gravity load to the lake bottom and bank. The influence of the lake water seepage under different heights of water level is considered.

The mechanical parameters of the lithologies are listed in Table 1. All the mechanical parameters are acquired from laboratory tests, and the permeability is tested by pumping experiment in situ. Other parameters such as bulk and shear modulus that will be used in numerical modeling can be 


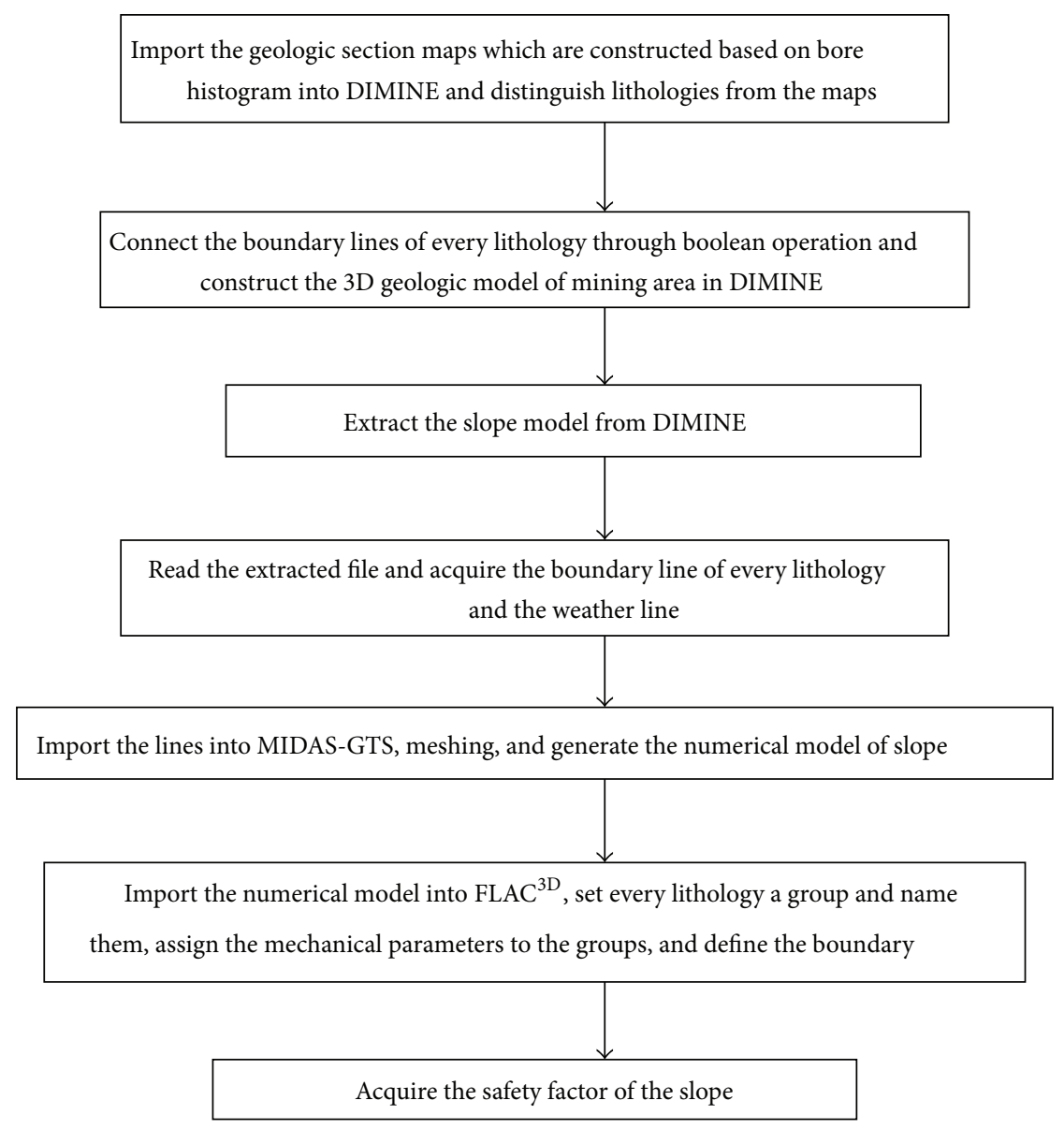

FIGURE 3: Flow of model development and calculation.

deduced by the former parameters. In numerical model, the mechanical parameters of unweathered limestone are different from the weathered limestone, and the porosity and permeability of Triassic limestone are treated different from Permian limestone.

\section{Numerical Modeling and Analysis}

4.1. Failure Criteria and Calculation Method. The strength reduction method (SRM) is adopted for the slope stability analysis associated with fluid flow. The SRM is based on the Mohr-Coulomb failure criterion. In the SRM, the definition of factor of safety is the ratio between the actual shear strength and the reduced shear strength at failure (1). Let the original strength parameters $c_{0}$ and $\varphi_{0}$ be divided by a strength reduction factor $R$, increasing or decreasing the value of $R$ until the critical failure state of slope. If strength parameters under critical failure state are $c_{\mathrm{cr}}$ and $\varphi_{\mathrm{cr}}$, then $R_{\mathrm{cr}}=1$, and the corresponding factor of safety is $F_{s}$ as follows:

$$
F_{s}=\frac{R}{R_{\mathrm{cr}}}=R=\frac{c_{0}}{c_{\mathrm{cr}}}=\frac{\tan \varphi_{0}}{\tan \varphi_{\mathrm{cr}}} .
$$

The fluid-mechanical interaction function of FLAC ${ }^{3 \mathrm{D}}$ [29] is adopted in the slope stability analysis, which can calculate the safety factor of the slope associating with fluid flow. In this function, rock mass is treated as a permeable solid and the flow modeling is independent of mechanical calculation. The fluid-mechanical interaction in $\mathrm{FLAC}^{3 \mathrm{D}}$ behaves in two mechanical effects. First, changes in pore pressure cause changes in effective stress and affect the response of the solid. Second, the fluid in a zone reacts to mechanical volume changes by a change in pore pressure. Fluid flow in the porous media is based on Darcy's law, processing Biot equation to describe fluid-solid interaction. Changes in the variation of fluid content are related to changes in pore pressure, $p$, saturation, $s$, mechanical volumetric strains, $\varepsilon$, and temperature, $T$. the response equation for the pore fluid is formulated as follows:

$$
\frac{1}{s} \frac{\partial \zeta}{\partial t}-\alpha \frac{\partial \varepsilon}{\partial t}+\beta \frac{\partial T}{\partial t}=\frac{1}{M} \frac{\partial p}{\partial t}+\frac{n}{s} \frac{\partial s}{\partial t},
$$

where $M$ is Biot modulus, $n$ is the porosity, $\alpha$ is Biot coefficient, and $\beta$ is the undrained thermal coefficient. The fluid mass balance can be expressed as follows:

$$
\frac{\partial \zeta}{\partial t}=-q_{i, i}+q_{v}
$$

where $q_{v}$ is the volumetric fluid source intensity, $\zeta$ is the variation of fluid content, and $-q_{i, i}$ is the fluid seepage 


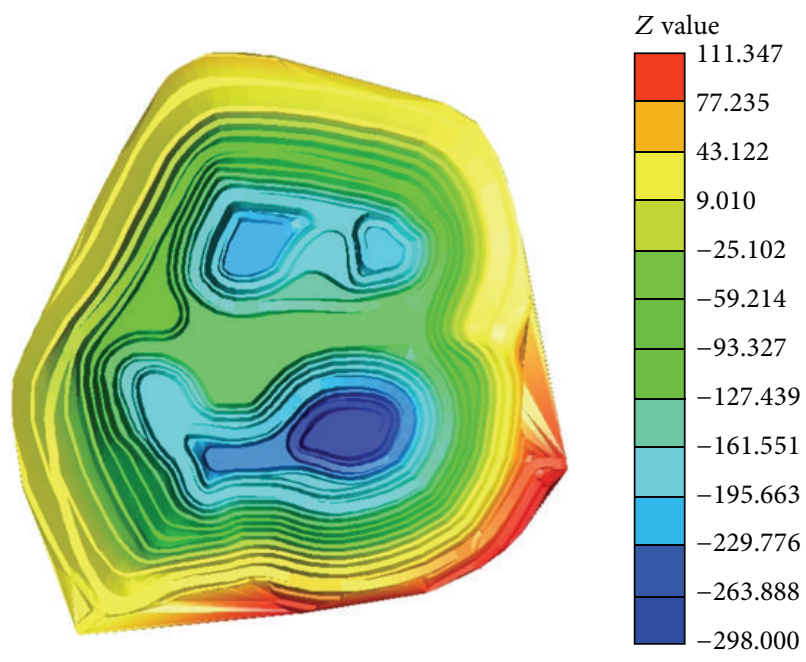

(a) Outline surface of the open-pit slope

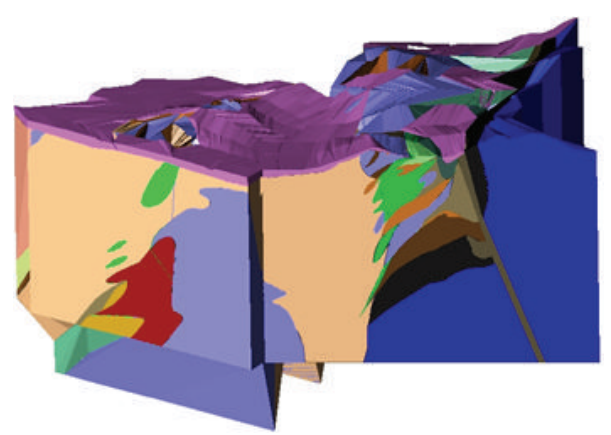

(b) 3-dimensional geological of the open-pit mine

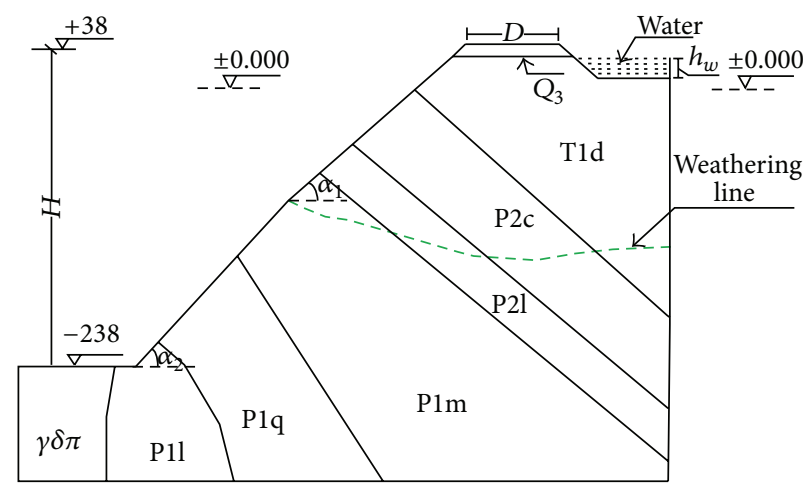

(c) The lithology boundary lines in the model

Figure 4: The model construction flow in DIMINE. Notations: $Q_{3}$ : Quaternary upper Pleistocene Series; T1d: Triassic Daye limestone; P2c: Permian Changxing limestone; P21: Permian Longtan limestone; P1m: Permian Maokou limestone; P1q: Permian Qixia limestone; P1l: Permian Liangshan limestone; $\gamma \delta \pi$ : Yanshanian granodiorite-porphyry; $H$ : height of the whole slope; $h_{w}$ : the depth of lake water; $D$ : distance between lake and slope; $\alpha_{1}$ : the average angle of weathered stage of open-pit slope; $\alpha_{2}$ : the average angle of unweathered stage of open-pit slope.

TABLE 1: Mechanical parameters of the rock formations contained in numerical model.

\begin{tabular}{|c|c|c|c|c|c|c|c|c|c|}
\hline Lithology & $\begin{array}{l}\text { Weathering } \\
\text { degree }\end{array}$ & $\begin{array}{l}\text { Density } \gamma \\
\left(\mathrm{kN} / \mathrm{m}^{3}\right)\end{array}$ & $\begin{array}{l}\text { Cohesion } \\
c(\mathrm{kPa})\end{array}$ & $\begin{array}{c}\text { Friction } \\
\text { angle } \varphi\left(^{\circ}\right)\end{array}$ & $\begin{array}{c}\text { Elasticity modulus } \\
E(\mathrm{GPa})\end{array}$ & $\begin{array}{l}\text { Poisson's } \\
\text { ratio } \mu\end{array}$ & $\begin{array}{l}\text { Porosity } \\
(\%)\end{array}$ & $\begin{array}{l}\text { Dilation } \\
\text { angle }\left({ }^{\circ}\right)\end{array}$ & $\begin{array}{c}\text { Permeability } \\
k(\mathrm{~cm} / \mathrm{s})\end{array}$ \\
\hline Quaternary & Weathered & 18.4 & 31.2 & 19.1 & 0.019 & 0.32 & 45 & 7 & $5.00 E-03$ \\
\hline $\begin{array}{l}\text { Granodiorite } \\
\text { porphyry }\end{array}$ & Unweathered & 28 & 440.1 & 29 & 40 & 0.22 & 10 & 24 & $3.30 E-04$ \\
\hline \multirow{2}{*}{$\begin{array}{l}\text { Triassic } \\
\text { limestone }\end{array}$} & Unweathered & 27 & 411.3 & 34 & 28.5 & 0.27 & 25 & 14 & $1.87 E-03$ \\
\hline & Weathered & 25 & 180 & 29 & 25.4 & 0.3 & 31.25 & 17 & $2.13 E-03$ \\
\hline \multirow{2}{*}{$\begin{array}{l}\text { Permian } \\
\text { limestone }\end{array}$} & Unweathered & 27 & 411.3 & 34 & 28.5 & 0.27 & 29.6 & 14 & $2.03 E-03$ \\
\hline & Weathered & 25 & 180 & 29 & 25.4 & 0.3 & 37 & 17 & $2.53 E-03$ \\
\hline
\end{tabular}

velocity. In FLAC ${ }^{3 \mathrm{D}}$ numerical approach, the flow domain is discretized into brick-shaped zones defined by eight nodes. Both pore pressure and saturation are assumed to be nodal variables. The contour of original pore pressure of the slope is shown in Figure 6.
4.2. Modeling Conditions. According to historical hydrology data, the lowest water level of Sai Lake corresponds to a depth of $2.4 \mathrm{~m}$, and the highest level corresponds to a depth of $17.2 \mathrm{~m}$. In order to estimate the influence of different depth of water to slope stability, five kinds of water levels of Sai Lake 


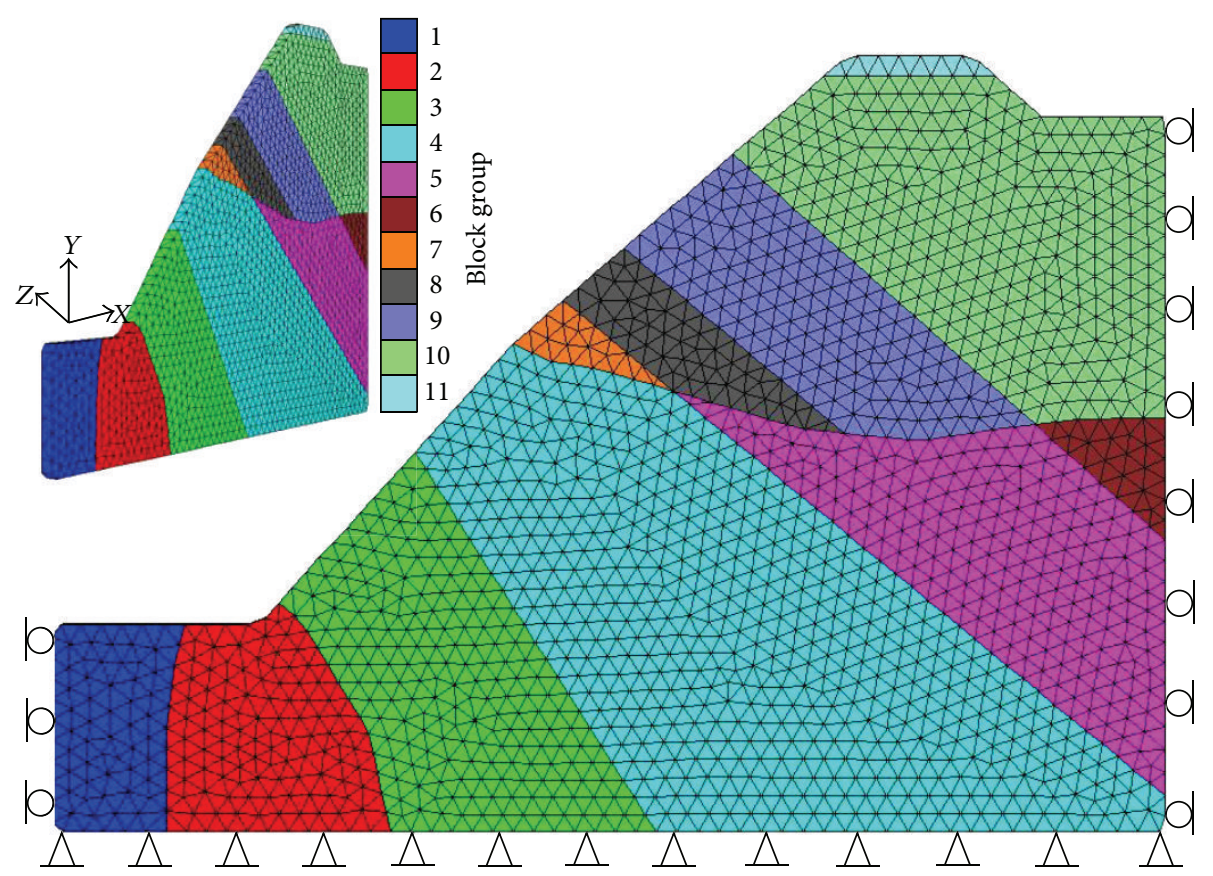

FIGURE 5: Numerical model of the slope in FLAC ${ }^{3 \mathrm{D}}$.

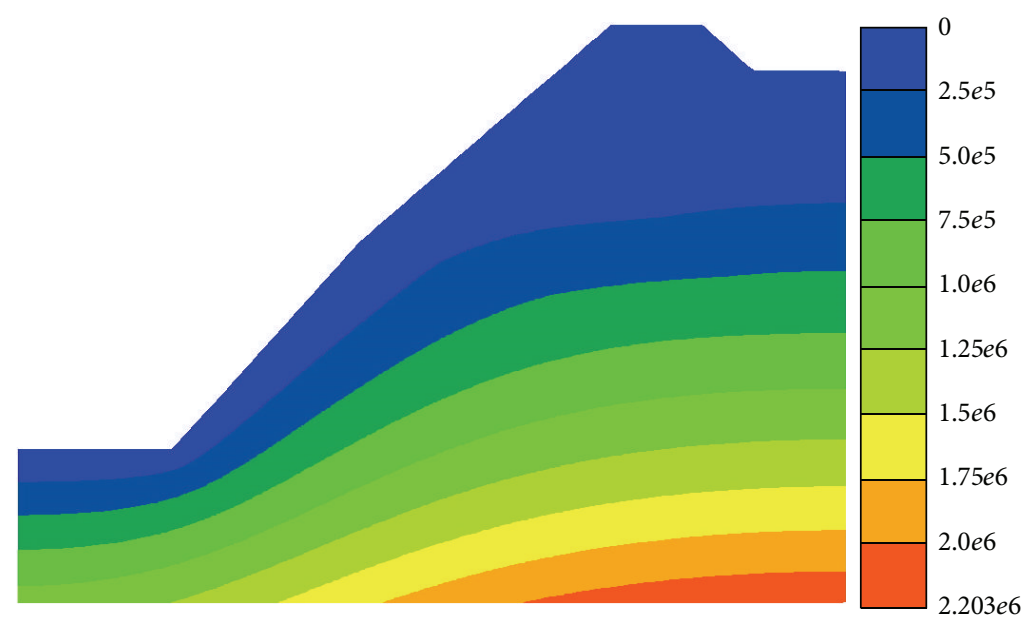

FIgURE 6: The contour of original pore pressure of the slope $\left(h_{w}=17, D=40 \mathrm{~m}\right)$.

are modeled: $h_{w}=17.2 \mathrm{~m}, h_{w}=12 \mathrm{~m}, h_{w}=7 \mathrm{~m}, h_{w}=2.4 \mathrm{~m}$, and $h_{w}=0 \mathrm{~m}$. In addition, the slope without water is modeled for comparison.

The influence of lake on slope stability is related to water seepage path and the distance between the open-pit slope and the lake bank $(D)$, which is the crucial factor to the seepage. The safe distance is acquired through analyzing the stability of slope under different values of $D$ and water level. Models of different lake-slope distances are established by moving the designed slope outline from the lake bank to inland. Specifically, four kinds of $D$ are modeled in numerical analysis, including $D=20 \mathrm{~m}, D=40 \mathrm{~m}, D=60 \mathrm{~m}$, and $D=80 \mathrm{~m}$.
4.3. Role of Lake Water Level on Slope Stability. The contour of shear strain increment after $F_{s}$ solution in FLAC $^{3 \mathrm{D}}$ of the slope in the condition of $D=20 \mathrm{~m}, h_{w}=2 \mathrm{~m}$ is shown in Figure 7. The slip surface of the slope is marked out in dotted lines. Because the slope is divided into two stages, the weathered stage and the unweathered stage, the failure surface behaves in two stages as well. The two failure surface stages connect with each other at the weathering line. The slip surface can be shown by the contour of shear strain increment [29]. Through connecting the mutation point of the shear strain increment, the slip surface is shown approximately, Figure 7. In follows of the passage, the slip failure surface of slope is shown in the form of dotted line as Figure 7. 


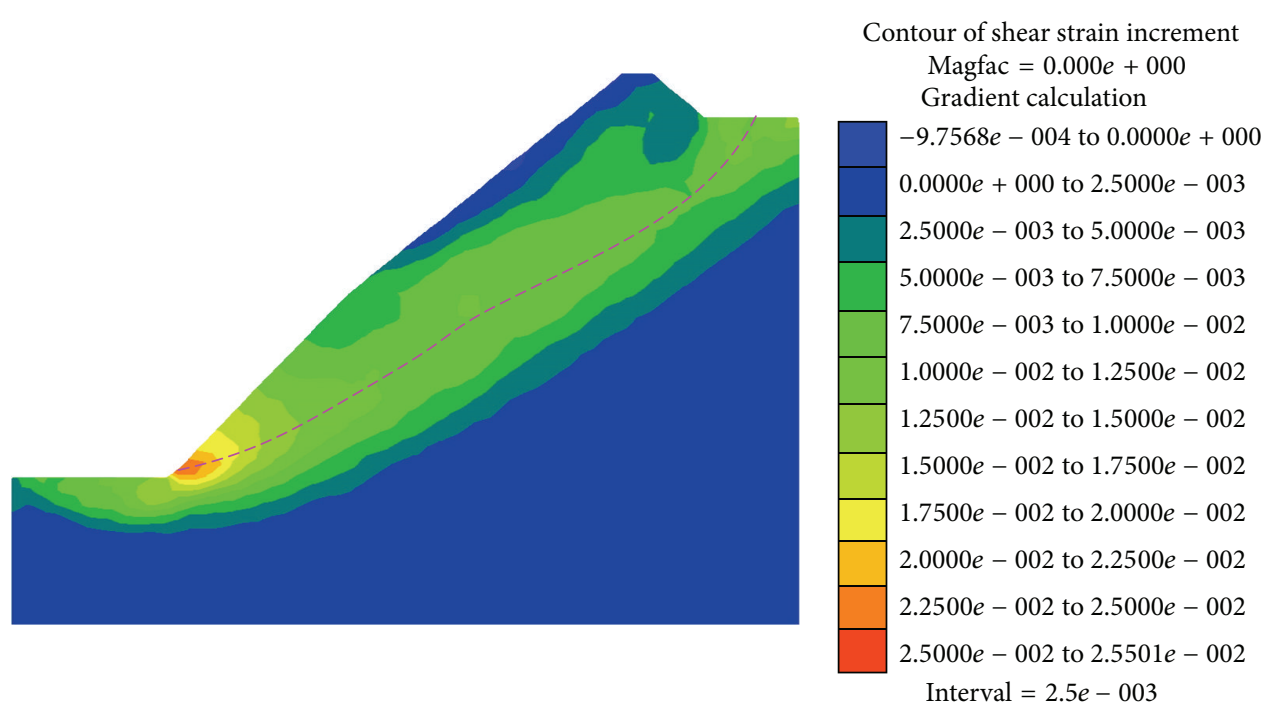

FIGURE 7: The contour of shear strain increment in the failure slope.

The failure modes of slope under conditions of different distances and water levels are shown in Figure 8. The numerical results indicate that the height of lake water level has great influence on the failure mode of the open-pit slope. It can be learned from Figure 8(a) that the slope without water has the minimum failure area, with the water level increasing the failure surface moving towards lake. When the water level increases to $2.4 \mathrm{~m}$ and $7 \mathrm{~m}$, the slopes slip from the lake bottom to the open-pit bottom. When the water level increases to $12 \mathrm{~m}$ and $17.2 \mathrm{~m}$, the slope failure just exits in the weathered area from the lake bank foot to the weathering line. The slope of $D=40 \mathrm{~m}$ (Figure 8(b)) and $h_{w}=0 \mathrm{~m}$ and dry slope slide from the open-pit bottom to the lake bank, and the slip area of others extends to the lake bank foot. When the distance increases to $60 \mathrm{~m}$, the failure modes can be seen in Figure 8(c). The top original failure point of slopes corresponding to $h_{w}=2.4 \mathrm{~m}$ and $h_{w}=0 \mathrm{~m}$ and dry locates at the lake bank peak point, with the water level elevating the top point to the lake bank bottom. The situation of $D=80 \mathrm{~m}$ is shown in Figure 8(d); slopes under the condition of $h_{w}=$ $2.4 \mathrm{~m}$ and $h_{w}=0 \mathrm{~m}$ and dry slide from the slope foot to the middle area of the slope top face.

It can be learned from the comparison of different slope failure modes that variable heights of lake water level have different influence on the slope failure modes. But as the same result the higher the lake water level, the larger the failure region that also means a greater destructive catastrophe. Once the slope slipped, immeasurable water would flow into the open-pit and it would be a disaster to the mine. Above all, a safe distance between lake and open-pit has significant meaning to Chengmenshan copper mine.

4.4. Determination of Minimum Lake-Slope Distance. The safety factor $\left(F_{s}\right)$ of slopes under different distances is numerically calculated by SRM in FLAC ${ }^{3 \mathrm{D}}$; the results are listed in Table 2. The $F_{s}$ values of slopes without the influence of lake water exceed 1.41 which is far larger than $F_{s}$ of slopes under the seepage of lake water. Dry slope of $D=80$ has the best
TABLE 2: Safety factor of slope under different $D$ and $h_{w}$.

\begin{tabular}{lcccc}
\hline $\begin{array}{l}\text { Height of water } \\
\text { level }(\mathrm{m})\end{array}$ & $D=20 \mathrm{~m}$ & $D=40 \mathrm{~m}$ & $D=60 \mathrm{~m}$ & $D=80 \mathrm{~m}$ \\
\hline Dry & 1.41992 & 1.41211 & 1.41911 & 1.43555 \\
17.2 & 1.091797 & 1.14648 & 1.18945 & 1.24367 \\
12 & 1.12695 & 1.17383 & 1.20117 & 1.25711 \\
7 & 1.18945 & 1.2207 & 1.25586 & 1.28805 \\
2.4 & 1.20898 & 1.24023 & 1.25965 & 1.28911 \\
0 & 1.25586 & 1.26758 & 1.27501 & 1.29492 \\
\hline
\end{tabular}

stability corresponding to $F_{s}$ value of 1.4355 . It means that the water weakens the slope stability seriously.

The $F_{s}$ variation trend of slopes under the influence of different heights of lake water is shown in Figure 9. The $F_{s}$ values of slopes under the seepage of lake water are all lower than 1.30. The maximum $F_{s}$ value of 1.29492 belongs to the slope of $h_{w}=0 \mathrm{~m}, D=80 \mathrm{~m}$, and the minimum $F_{s}$ value corresponds to the slope of $h_{w}=17.2 \mathrm{~m}, D=20 \mathrm{~m}$. Under the condition of the same lake-slope distance, the $F_{s}$ value decreases with the lake water level rising. To every lake-slope distance, $F_{s}$ value reaches the minimum when the water level rises to $17.2 \mathrm{~m}$.

By comparing the $F_{s}$ values of slopes under the same lake water level but different lake-slope distances, it can be noted that the larger the lake-slope distances, the better the slope stability. This indicates that the lake-slope distance has some influence in the weakening effect of the lake water on openpit slopes.

The variation range of $F_{s}$ values of different lake-slope distances increases with the decreasing of lake-slope distance. In order to analyze the sensitivity of slope stability to the lake water level, the parameter $\Delta$ is defined as the weakening degree of the slope $F_{s}$ under the seepage of lake water, expressed as (4). $F_{S D}$ represents $F_{s}$ of dry slope and $F_{S W}$ represents $F_{s}$ of slope containing lake water. A larger $\Delta$ means 

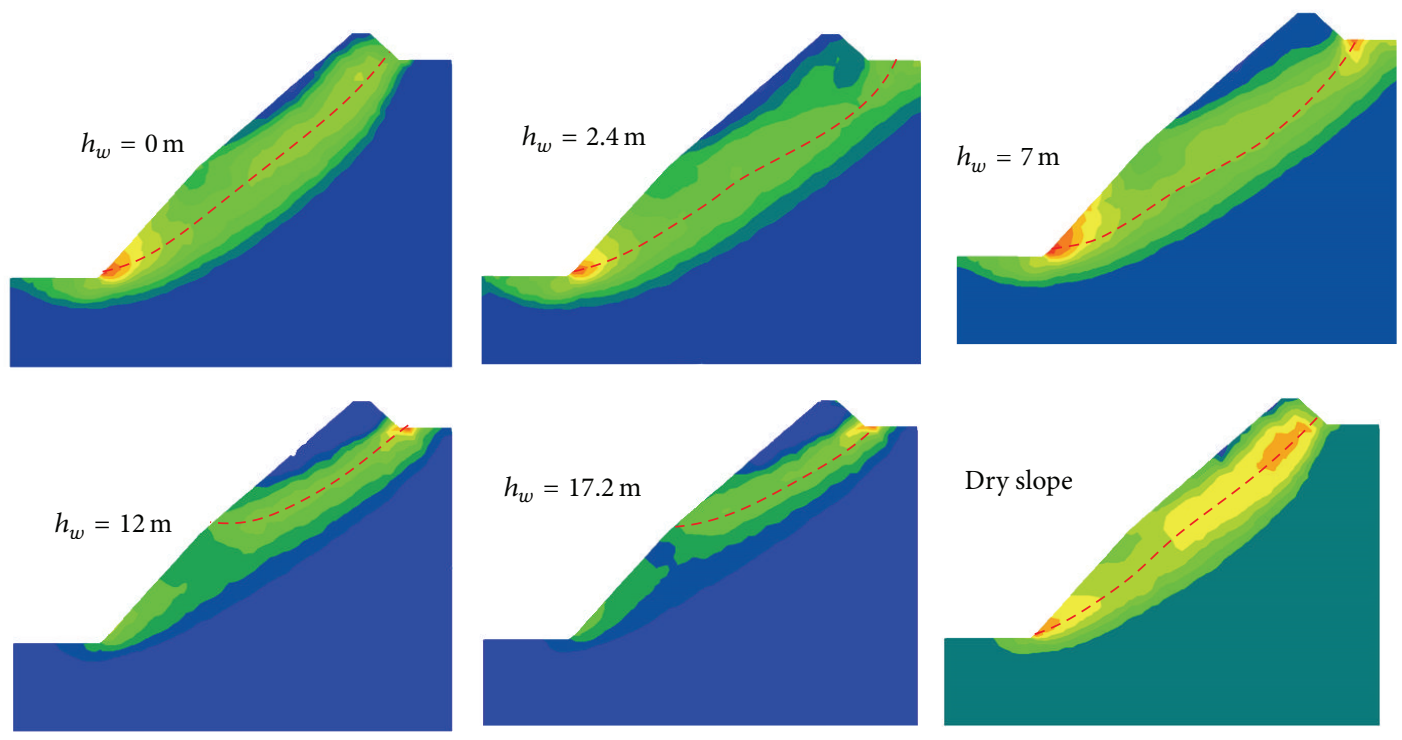

(a) $D=20 \mathrm{~m}$
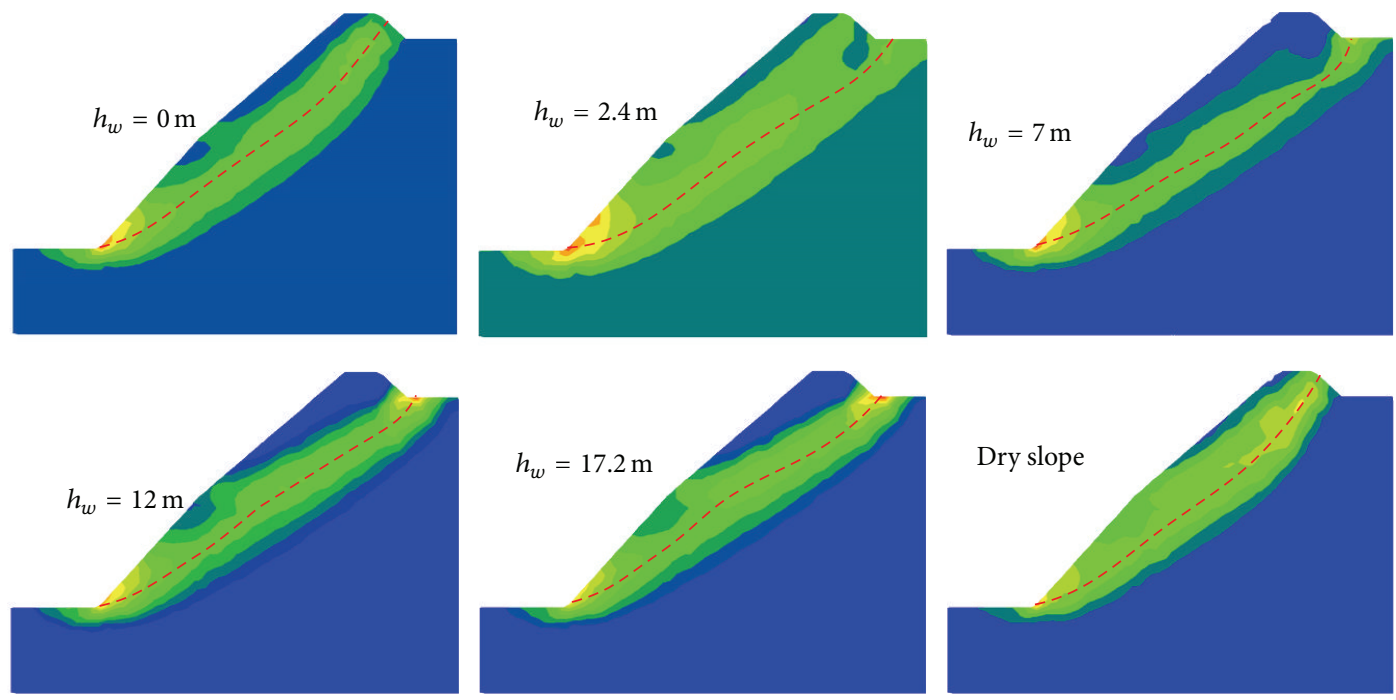

(b) $D=40 \mathrm{~m}$
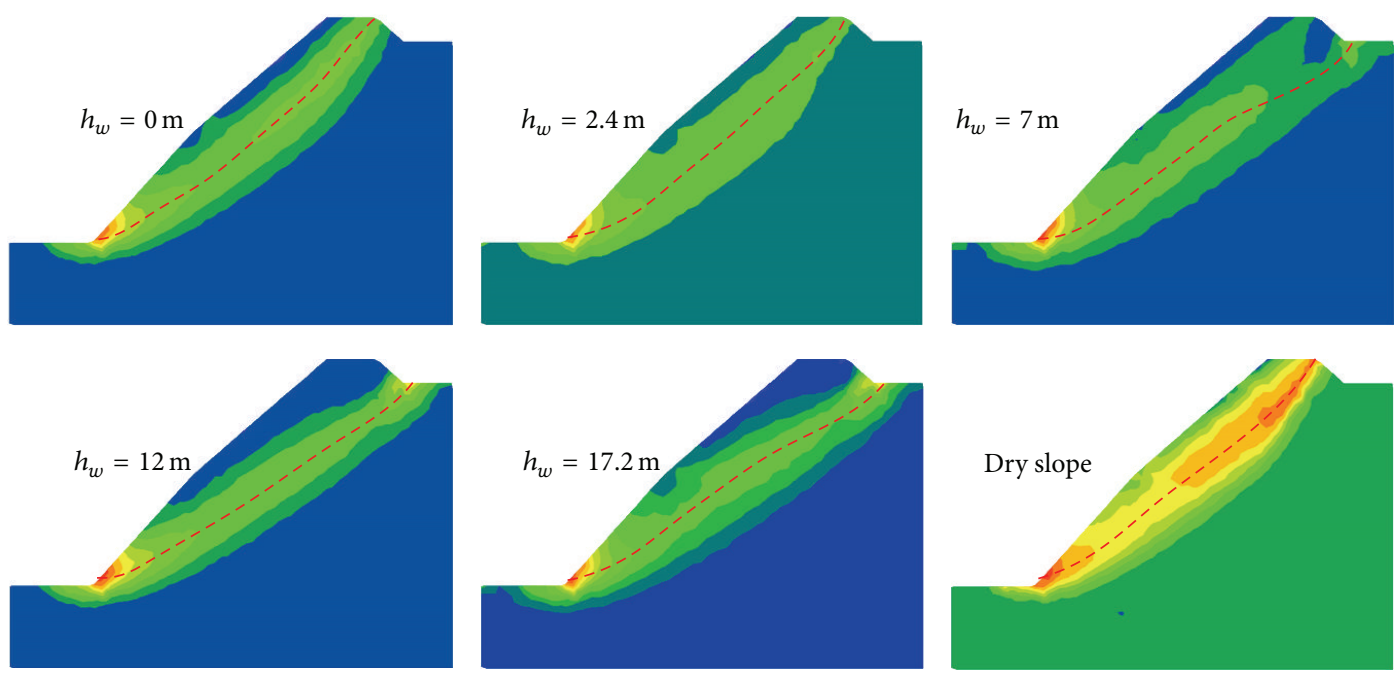

(c) $D=60 \mathrm{~m}$

Figure 8: Continued. 

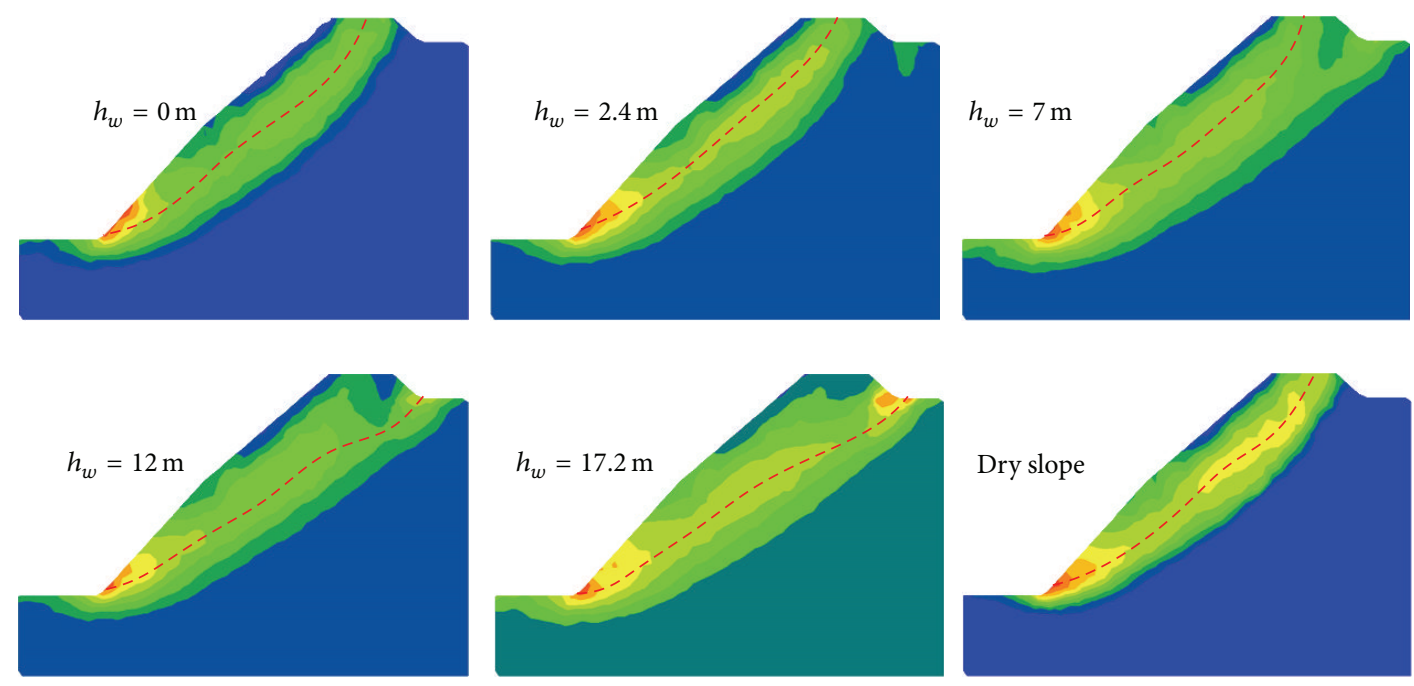

(d) $D=80 \mathrm{~m}$

FIGURE 8: The effect of water level on the location of critical failure surface.

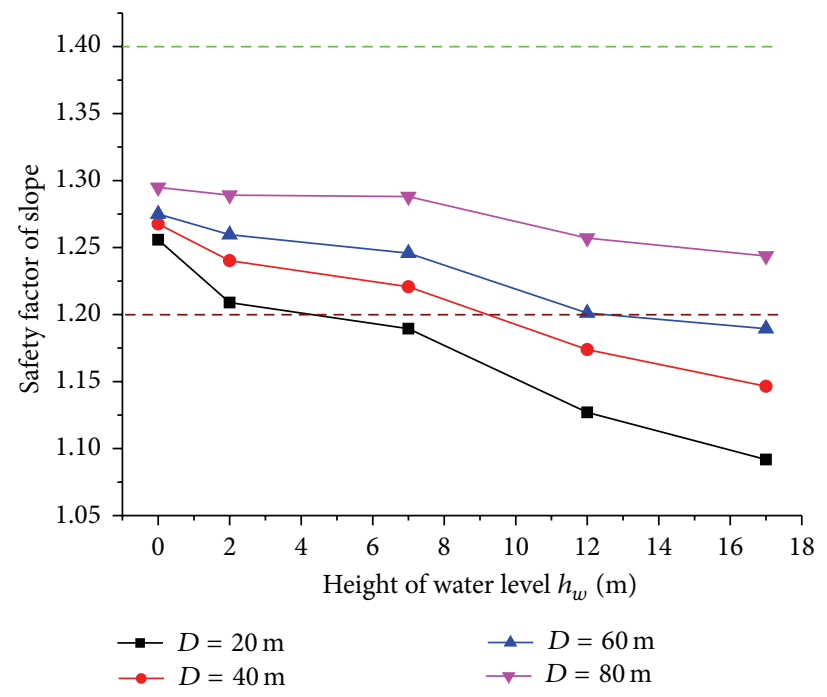

FIGURE 9: Safety factor of slope under different height of water level and distance between lake and open-pit slope.

the slope stability is more susceptible to the height of lake water level. The $\Delta$ values of slopes under every condition are shown in Figure 10. To the slope of $D=20 \mathrm{~m}$, the minimum and maximum $\Delta$ values are $11.6 \%$ and $23.3 \%$, respectively. To the slope of $D=80 \mathrm{~m}$, the minimum and maximum $\Delta$ values are $9.8 \%$ and $13.4 \%$, respectively. The varying trend is evident that $\Delta$ gets smaller as the lake-lope distance gets larger. The weakening degree of $F_{s}$ gets lower when the slope locates further from the Sai Lake. This indicates that with the slope getting closer to Sai Lake, the slope is more sensitive to the lake water. Thus, a reasonable lake-slope distance is needed to make sure a safe environment of underground mining and keep the slope insensitive to the lake water:

$$
\Delta=\frac{F_{S D}-F_{S W}}{F_{S D}} \times 100 \% .
$$

In the design plan of Chengmenshan open-pit slope, $F_{s}=$ 1.20 is adopted as the allowable safety factor for slope design. According to Figure 9, as for the slope of $D=60 \mathrm{~m}, F_{s}$ of the most dangerous condition is 1.18945 which is close to 1.20 , and when the water level gets lower than $17.2 \mathrm{~m}$, the safety factor increases to larger than 1.20. With respect to the slope of $D=80 \mathrm{~m}$, the $F_{s}$ of slope under every height of water level is much larger than 1.20. The larger $F_{s}$ value means a greater diminution of the open-pit area. Furthermore, the condition of $D=20 \mathrm{~m}$ and $D=40 \mathrm{~m}$ cannot ensure every $F_{s}$ value larger than 1.20. In conclusion, $D=60$ is determined as the minimum lake-slope distance.

4.5. Role of Slope Height on Slope Stability. As the height of open-pit slope is $58 \mathrm{~m}$ at present, the height will increase to $238 \mathrm{~m}$ until the completion of slope engineering. In order to 


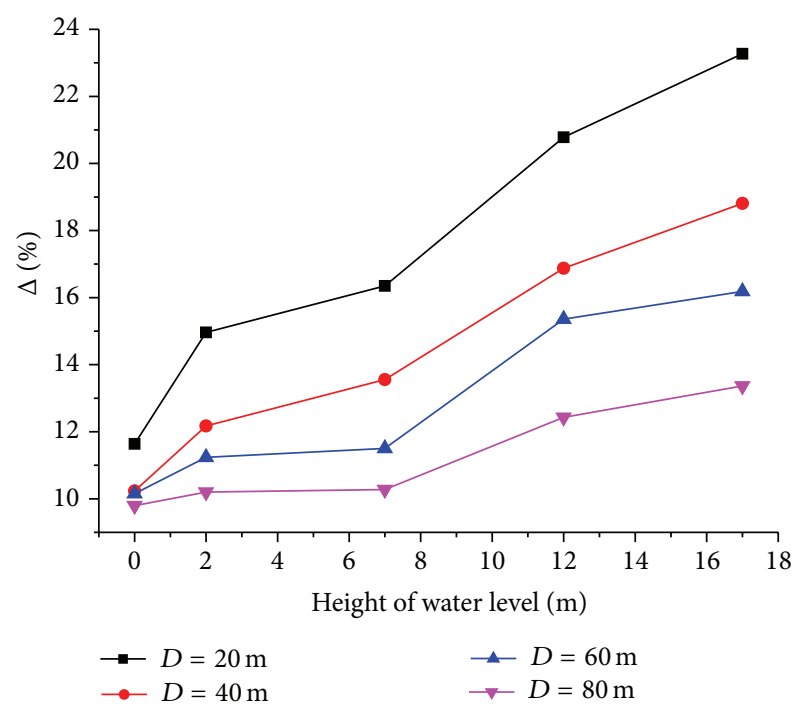

FIGURE 10: The variation of $\Delta$ under different $D$ and $h_{w}$.

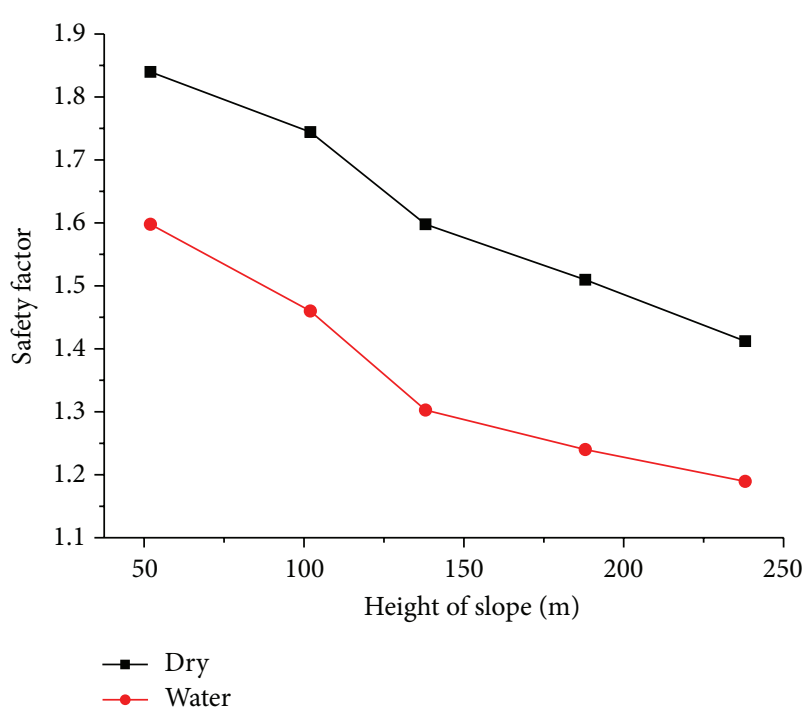

FIGURE 11: Comparison of $F_{s}$ between dry slope and slope of $h_{w}=$ $17.2 \mathrm{~m}$ under different slope heights.

evaluate the stability of slopes under the influence of lake water during the excavation, different heights of slopes under the condition of $D=60 \mathrm{~m}$ and $h_{w}=17.2 \mathrm{~m}$ and irrespective of water are numerically modeled; the $F_{s}$ values are shown in Figure 11. As the slope height increases, the slope stability gets worse. $F_{s}$ values of the highest slopes with and without lake water seepage are 1.4191 and 1.18945, respectively. From the comparison of $F_{s}$ between dry slope and slope of $h_{w}=17.2 \mathrm{~m}$, it can be learned that the seepage weakened the slope stability almost in the same degree.

\section{Conclusions}

Based on the drill data and geological sections of exploration line, a 3-dimensional geological model of the lakeside openpit slope is established by DIMINE. Through a flow of
DIMINE $\rightarrow$ MIDAS $\rightarrow$ FLAC $^{3 \mathrm{D}}$, the numerical model of the slope is built. The seasonally changed water level of Sai Lake and the distance between lake and open-pit slope have been considered in the numerical analysis.

The numerical analysis results show that the lake water near the open-pit has great influence on the slope stability. With the water level rising, the $F_{s}$ value of the slope decreases, and when the water level rises to the historically recorded highest of $17.2 \mathrm{~m}$, the slope will get to the most dangerous situation. The stabilities of slopes under different lake-slope distance $(D=20 \mathrm{~m}, 40 \mathrm{~m}, 60 \mathrm{~m}$, and $80 \mathrm{~m})$ are compared. The distance plays some role in the weakening effect of the lake water on open-pit slope; that is, the larger the distance, the better the slope stability. The weakening degree coefficient $\Delta$ is defined to evaluate the sensitivity of slope $F_{s}$ to water under different lake-slope distance. The larger the distance is, the weaker the effect of lake water seepage on the slope stability performs. The stabilities of slopes of different heights are analyzed, and it is discovered that, with the height increasing, the slope stability reduces greatly, and the saturation effect on slope stability is enhanced. To the highest slope of $H=238 \mathrm{~m}$ under a lake water level of $17.2 \mathrm{~m}$, the $F_{s}$ value is 1.18945 , which is extremely closed to 1.20 . According to the allowable safety factor for slope design, the minimum distance between lake and open-pit slope is found to be $60 \mathrm{~m}$.

\section{Conflict of Interests}

The authors declare that there is no conflict of interests regarding the publication of this paper.

\section{Acknowledgments}

The authors would like to acknowledge the financial supports from Project no. 51274249 supported by National Natural Science Foundation of China and Project 20120162110009 supported by the Specialized Research Fund for the Doctoral Program of Higher Education of China. The contribution of the Jiangxi Copper Industry Group Co. at Chengmenshan copper mine is gratefully acknowledged.

\section{References}

[1] W. C. Zhu, J. Liu, T. H. Yang, J. C. Sheng, and D. Elsworth, "Effects of local rock heterogeneities on the hydromechanics of fractured rocks using a digital-image-based technique," International Journal of Rock Mechanics and Mining Sciences, vol. 43, no. 8, pp. 1182-1199, 2006.

[2] S. Y. Wang, L. Sun, A. S. K. Au, T. H. Yang, and C. A. Tang, "2Dnumerical analysis of hydraulic fracturing in heterogeneous geo-materials," Construction and Building Materials, vol. 23, no. 6, pp. 2196-2206, 2009.

[3] Itasca Consulting Group, Particle Flow Code, User Manual, Version 3.0, Itasca Consulting Group, 2004.

[4] L. C. Li, C. A. Tang, S. Y. Wang, and J. Yu, "A coupled thermohydrologic-mechanical damage model and associated application in a stability analysis on a rock pillar," Tunnelling and Underground Space Technology, vol. 34, pp. 38-53, 2013.

[5] Itasca Consulting Group, Fast Lagrangian Analysis of Continua in 3 Dimensions, User Manual, Version 3.0, Itasca Consulting Group, 2004. 
[6] S. Stegmann, N. Sultan, A. Kopf, R. Apprioual, and P. Pelleau, "Hydrogeology and its effect on slope stability along the coastal aquifer of Nice, France," Marine Geology, vol. 280, no. 1-4, pp. 168-181, 2011.

[7] J. J. Jiao, X.-S. Wang, and S. Nandy, "Confined groundwater zone and slope instability in weathered igneous rocks in Hong Kong," Engineering Geology, vol. 80, no. 1-2, pp. 71-92, 2005.

[8] Z.-M. Jiang, X.-H. Xiong, and L. Zeng, "Unsaturated seepage analysis of slope under rainfall condition based on FLAC ${ }^{3 \mathrm{D}}$," Rock and Soil Mechanics, vol. 35, no. 3, pp. 855-861, 2014.

[9] J.-R. Xie, C.-Y. Zhou, and Y. Cheng, "Method of seepagesoftening analysis and disaster mechanism in soft rock slope under rainfall," Rock and Soil Mechanics, vol. 35, no. 1, pp. 197210, 2014.

[10] O. Stephansson, J. A. Hudson, and L. Jing, Coupled ThermoHydro-Mechanical-Chemical Processes in Geo-Systems: Fundamentals, Modelling, Experiments and Applications, Elsevier, Amsterdam, The Netherlands, 2004.

[11] J. C. Stormont and J. J. K. Daemen, "Laboratory study of gas permeability changes in rock salt during deformation," International Journal of Rock Mechanics and Mining Sciences \& Geomechanics Abstracts, vol. 29, no. 4, pp. 325-342, 1992.

[12] S. E. Minkoff, C. M. Stone, S. Bryant, M. Peszynska, and M. F. Wheeler, "Coupled fluid flow and geomechanical deformation modeling," Journal of Petroleum Science and Engineering, vol. 38, no. 1-2, pp. 37-56, 2003.

[13] J. Rutqvist and O. Stephansson, "The role of hydromechanical coupling in fractured rock engineering," Hydrogeology Journal, vol. 11, no. 1, pp. 7-40, 2003.

[14] H. F. Wang, Theory of Linear Poroelasticity, Princeton University Press, 2000.

[15] T. D. Sullivan, "Understanding pit slope movements," in Geotechnical Instrumentation and Monitoring in Open Pit and Underground Mining, T. Szwedzicki, Ed., Balkema, Rotterdam, The Netherlands, 1993.

[16] T. D. Sullivan, "Mine slope design-the chances of getting the answer right and the risk of getting it wrong," in Proceedings of the 4th Large Open Pit Mining Conference, Perth, Australia, 1994.

[17] T. D. Sullivan, "Pit slope design and risk-a view of the current state of the art," in Proceedings of the International Symposium on Stability of Rock Slopes in Open Pit Mining and Civil Engineering, vol. 544 of Symposium Series, The South African Institute of Mining and Metallurgy, Cape Town, South Africa, 2006.

[18] M. Sartori, F. Baillifard, M. Jaboyedoff, and J.-D. Rouiller, "Kinematics of the 1991 Randa rockslides (Valais, Switzerland)," Natural Hazards and Earth System Science, vol. 3, no. 5, pp. 423433, 2003

[19] F. Cappa, Y. Guglielmi, P. Fénart, V. Merrien-Soukatchoff, and A. Thoraval, "Hydromechanical interactions in a fractured carbonate reservoir inferred from hydraulic and mechanical measurements," International Journal of Rock Mechanics \& Mining Sciences, vol. 42, no. 2, pp. 287-306, 2005.

[20] Z. Saada, S. Maghous, and D. Garnier, "Stability analysis of rock slopes subjected to seepage forces using the modified HoekBrown criterion," International Journal of Rock Mechanics \& Mining Sciences, vol. 55, pp. 45-54, 2012.

[21] X. Lv, Z. Wang, and J. Wang, "Seepage-damage coupling study of the stability of water-filled dump slope," Engineering Analysis with Boundary Elements, vol. 42, pp. 77-83, 2014.

[22] M. L. Chu-Agor, G. A. Fox, R. M. Cancienne, and G. V. Wilson, "Seepage caused tension failures and erosion undercutting of hillslopes," Journal of Hydrology, vol. 359, no. 3-4, pp. 247-259, 2008.

[23] A. Srivastava, G. L. S. Babu, and S. Haldar, "Influence of spatial variability of permeability property on steady state seepage flow and slope stability analysis," Engineering Geology, vol. 110, no. 34, pp. 93-101, 2010.

[24] H. Lin, P. Cao, J.-T. Li, X.-L. Jiang, and Z.-M. He, "Automatic generation of FLAC3D model based on SURPAC," Journal of China University of Mining and Technology, vol. 37, no. 3, pp. 339-342, 2008 (Chinese).

[25] K. Liu, X. Li, F. Gong, X. Liu, and W. Wang, "Stability analysis of complicated cavity based on CALS and coupled SurpacFLAC3D technology," Chinese Journal of Rock Mechanics and Engineering, vol. 27, no. 9, pp. 1924-1931, 2008 (Chinese).

[26] Z.-Q. Luo, Y.-B. Wu, X.-M. Liu, W.-P. Liu, and B. Yang, "FLAC3D modeling for complex geologic body based on SURPAC," Rock and Soil Mechanics, vol. 29, no. 5, pp. 1334-1338, 2008 (Chinese).

[27] X. Li, D. Li, Z. Liu, G. Zhao, and W. Wang, "Determination of the minimum thickness of crown pillar for safe exploitation of a subsea gold mine based on numerical modelling," International Journal of Rock Mechanics and Mining Sciences, vol. 57, no. 3, pp. 42-56, 2013.

[28] M. Grenon and J. Hadjigeorgiou, "Integrated structural stability analysis for preliminary open pit design," International Journal of Rock Mechanics and Mining Sciences, vol. 47, no. 3, pp. 450460, 2010.

[29] Itasca Consulting Group, FLAC3D_Fast Lagrangian Analysis of Continua in 3 Dimensions, Version 3.0 Fluid-Mechanical Interaction, Itasca Consulting Group, Minneapolis, Minn, USA, 2005.

[30] Y. M. Cheng, T. Lansivaara, and W. B. Wei, "Two-dimensional slope stability analysis by limit equilibrium and strength reduction methods," Computers and Geotechnics, vol. 34, no. 3, pp. 137-150, 2007.

[31] W. B. Wei and Y. M. Cheng, "Stability analysis of slope with water flow by strength reduction method," Soils and Foundations, vol. 50, no. 1, pp. 83-92, 2010.

[32] H. Lin, P. Cao, F.-Q. Gong, J.-T. Li, and Y.-L. Gui, "Directly searching method for slip plane and its influential factors based on critical state of slope," Journal of Central South University of Technology, vol. 16, no. 1, pp. 131-135, 2009.

[33] W. X. Jian, Z. J. Wang, and K. L. Yin, "Mechanism of the Anlesi landslide in the Three Gorges Reservoir, China," Engineering Geology, vol. 108, no. 1-2, pp. 86-95, 2009. 


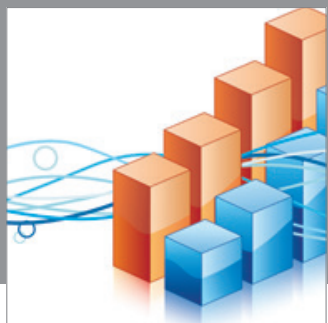

Advances in

Operations Research

mansans

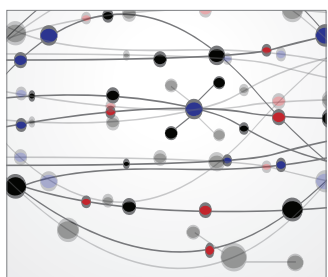

The Scientific World Journal
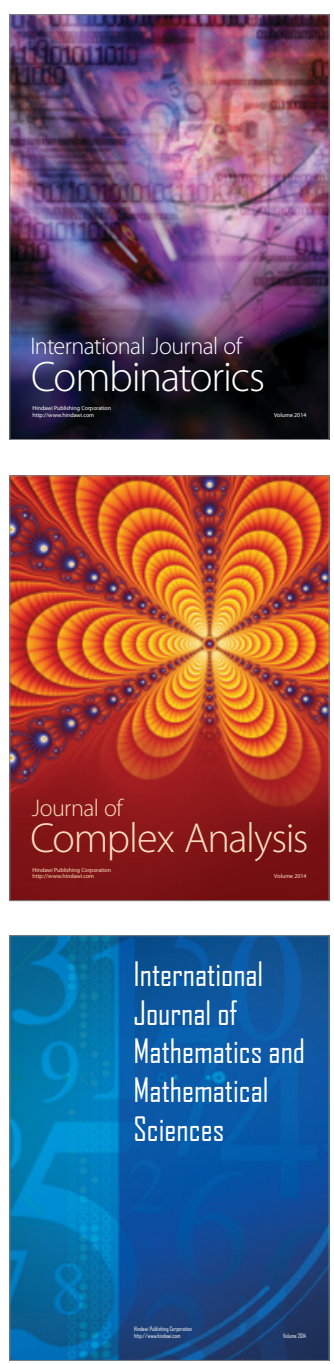
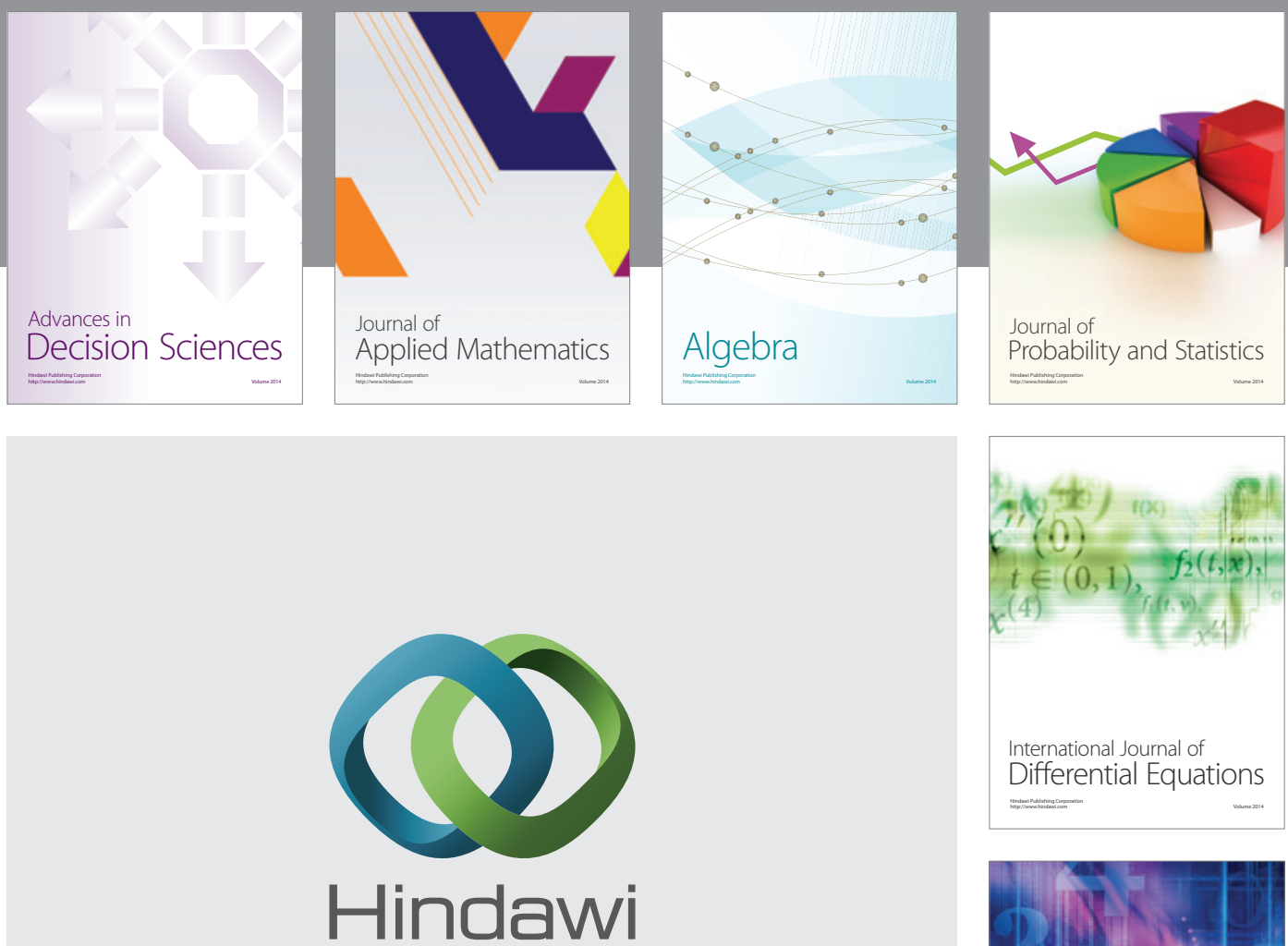

Submit your manuscripts at http://www.hindawi.com
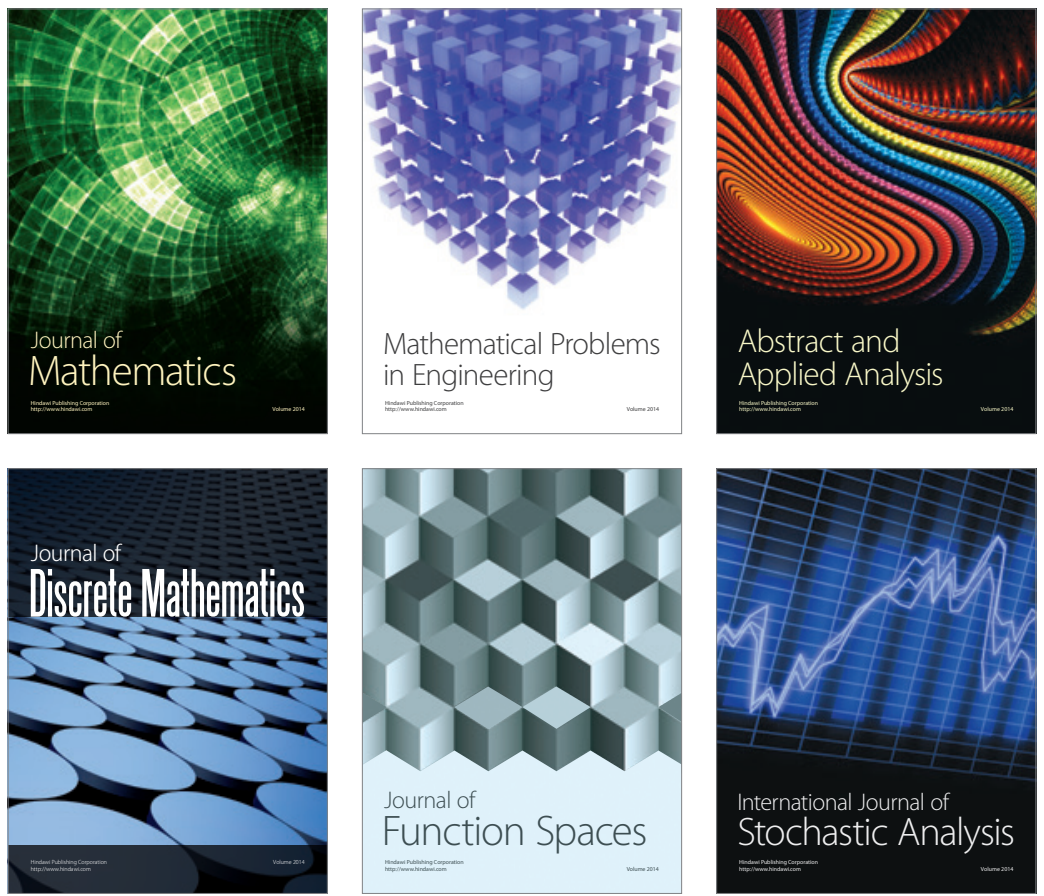

Journal of

Function Spaces

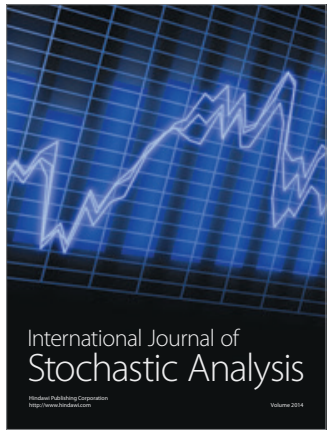

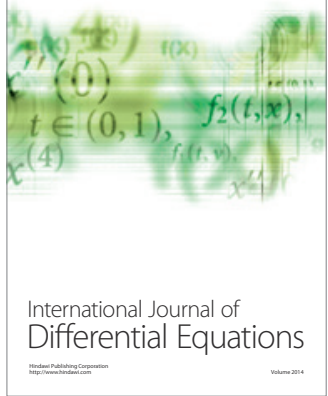
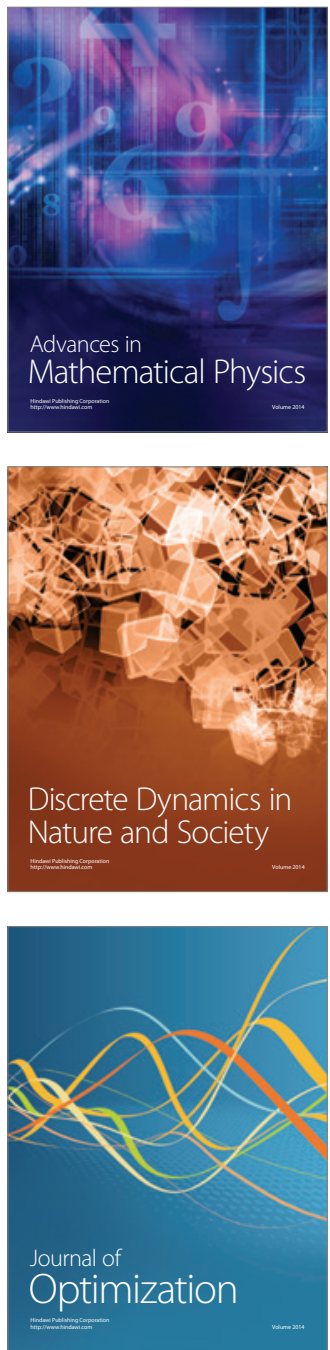